\title{
The Behavior of Carbon Steel in Artificial Cooling Water in Presence of Hydroxyphosphonoacetic Acid and Different Oxygen Content Using Electrochemical Impedance Spectroscopy
}

\author{
H. Castaneda ${ }^{*}, \mathrm{a}$, R. Hernández ${ }^{\mathrm{b}}$ and M. Galicia ${ }^{\mathrm{c}}$ \\ ${ }^{a}$ Battelle Memorial Institute, Energy Systems, 505 King Avenue, Columbus OH 43201, USA \\ ${ }^{b}$ Universidad Nacional Autónoma de México, Facultad de Química, Ingeniería Química Metalúrgica, Ciudad Universi- \\ taria, 04510, D.F. México \\ ${ }^{c}$ Programa de Explotación de Campos en Aguas Profundas, Instituto Mexicano del Petróleo, Eje Central L. Cárdenas \\ 152, 07730, D.F. México
}

\begin{abstract}
This paper presents the results of the interfacial evolution of 1018 steel exposed to artificial cooling water in presence of two different environments: the oxygen content and the 1,2-hydroxyphosphonoacetic acid (HPA). The aerated solution in presence of HPA supported two processes; the first was the sequestration of calcium ions with the subsequent complexation of the calcium carbonate $\left(\mathrm{CaCO}_{3}\right)$; the second was the precipitation of a layer formed mainly by hematite $\left(\mathrm{Fe}_{2} \mathrm{O}_{3}\right)$ mixed with $\mathrm{CaCO}_{3}$ and phosphorous-based compounds. Conversely, de-aerated conditions in the absence of HPA lead to the formation of a combination of iron oxides $\left(\mathrm{Fe}_{3} \mathrm{O}_{4}+\mathrm{Fe}_{2} \mathrm{O}_{3}\right)$ at the surface of the steel. The HPA addition in deaerated solution produced the formation of plate shape phosphorous-based layer with a mixture of iron oxides $\left(\mathrm{Fe}_{3} \mathrm{O}_{4}+\right.$ $\mathrm{Fe}_{2} \mathrm{O}_{3}$ ). In this work, we could characterize the evolution of the corrosion products layers by Electrochemical Impedance Spectroscopy (EIS) measurements and electrical passive circuits. The continuous EIS results helped to establish interfacial mechanisms of the HPA used as inhibitor and de-aerated (oxygen low content) conditions simulating the presence of oxygen scavengers.
\end{abstract}

Keywords: Inhibition mechanism, oxygen content, hydroxyphosphonoacetic acid, phosphorous corrosion products.

\section{INTRODUCTION}

Several studies for the dissolution process and formation of carbonate scale of mild steel in cooling water systems and heat exchangers [1-6] have led to new routes concerned to the mitigation of corrosion in the water treatment for refinery industry. One of the unsolved issues for corrosion control processes is the identification and development of mechanisms associated with the metallic inhibition reaction.

Calcium carbonate, $\mathrm{CaCO}_{3}$, precipitates as the product of homogeneous reactions onto cathodic surfaces in scaling solutions $[7,8]$. The mineral scale structure exists mainly in three different allotropic forms: aragonite, calcite and vaterite [9]. The scaling product is the result of the homogeneous reaction between the bicarbonate ion with calcium ions $[10,11]$ in neutral and high $\mathrm{pH}$ environments.

Corrosion control of steels in neutral solutions by inhibitors includes the formation of surface layers [12-14] that modifies the kinetics of the dissolution process. Lorenz and Mansfeld considered those layers as three dimensional (3-D) protective entities that initiated and grown on the electrode surface that influenced the electrode reactions $[12,13]$. They suggested that the inhibitors are incorporated in the 3-D layers within the metal-oxide interfaces, which lead to more

*Address correspondence to this author at the Energy Systems, 505 King Avenue, Columbus Ohio, 43201, USA; Tel: 614424 4794; Fax: 614458 4794; E-mail: castanedah@battelle.org homogeneous and denser corrosion products with less porosity [12]. Other approaches have demonstrated that the inhibition process can be controlled by the homogeneous reactions that sequestrate the species in solution influencing the corrosion process [10].

The most successful inhibitor formulations currently used for scaling conditions are based on phosphonates $[15,16]$ as they have shown excellent temperature and $\mathrm{pH}$ stability. The phosphonates have been excellent inhibitors when used at threshold concentration levels due to the complexation with cationic species, such as calcium and magnesium. Some inhibitors based on organic phosphonates and organic amino phosphates minimize scale deposition through a combination of crystal dispersion and scale stabilization [14].

An alternative form of corrosion control in scaling solutions is the reduction of dissolved oxygen content in the electrolyte; this latter influences the precipitation of insoluble iron complex on metal surface [17]. Chen et al. [18] have verified that the corrosion rate of steel in scaling solutions decreased in the presence of an oxygen scavenger where the percent scale formation was lowered by $96.2 \%$. Meng et al. [19] demonstrated that when adding inhibitor and oxygen scavenger the corrosion inhibition ability is improved. The importance of the role of the oxygen into the scaling solutions in the corrosion control for oil industry has led to the minimization of oxygen content [20,21].

This paper evidences the influence of oxygen content in the interfacial mechanisms for steel exposed in artificial 
cooling water in presence of 1, 2-hydroxyphosphonoacetic acid (HPA). Electrochemical Impedance Spectroscopy (EIS) is used (1) to characterize the evolution of corrosion products, and (2) to evaluate qualitatively two forms of inhibition processes with time. The dissolution-inhibition mechanism shows strong dependence on the oxygen content due to the formation of different iron oxides and the cathodic reaction involved at the interface. High-definition surface analysis supports the physical properties of the corrosion products under different electrolyte conditions. A phenomenological interfacial process is suggested based on the formation of corrosion product layers that influenced the electricalimpedance characteristics with time.

\section{MATERIALS AND METHODS}

\section{Electrochemical Cell}

A typical 3-electrode electrochemical cell including a standard $150 \mathrm{~mL}$ container was used in this work. The container had five inlet ports as displayed in Fig. (1). The ports included the working electrode, a graphite bar as the counter electrode, a saturated calomel electrode (SCE) as the reference electrode, a thermometer, inlet for inhibitor injection and port for nitrogen bubbling.

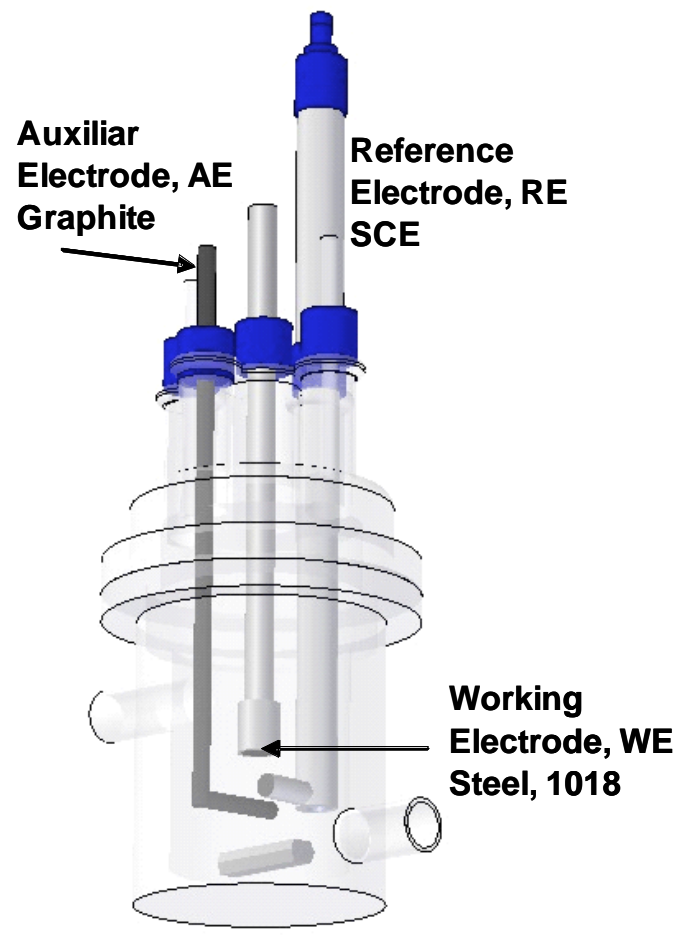

Fig. (1). Representation of the electrochemical cell.

The composition of cylindrical 1018 carbon steel sample used as working electrode is displayed in Table 1. The elec- trode-exposed area to the solution was $0.5 \mathrm{~cm}^{2}$. The electrode surface was polished at $1 \mu \mathrm{m}$ grade thereafter rinsed with distilled water and acetone.

Calcium chloride (360 ppm), magnesium sulphate (200 $\mathrm{ppm})$ and sodium bicarbonate $(100 \mathrm{ppm})$ were mixed to prepare synthetic cooling water in distilled water, according to a composition referred elsewhere [22].

\section{Inhibitor}

The HPA structure used as inhibitor is represented in Fig. (2), the concentration used was $125 \mathrm{ppm}$, which represents an example of the initial test concentrations in the use of inhibitors for refinery plants.

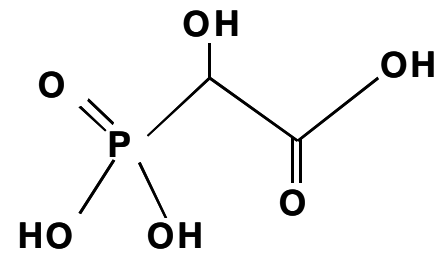

Fig. (2). Molecular structure of 1,2-hydroxyphosphonoacetic acid.

\section{Electrochemical Techniques}

The aerated experiments were performed in scaling solution with $2.3 \mathrm{ppm}$ of oxygen dissolved. De-aerated experiments were kept at 0.1-ppm oxygen content in the electrolyte.

Each set of the electrochemical testing included the open circuit potential (OCP) measurements over 90 hours.

Separately, EIS experiments were performed in duplicate; the set up conditions included the measurements at open circuit potential with $10 \mathrm{mV}$ of amplitude and frequencies ranging from $10 \mathrm{KHz}$ to $0.01 \mathrm{~Hz}$. The EIS measurements were performed every hour during the first 6 hours, and every 10 hours thereafter and up to 90 hours of total exposure time. EIS measurements in the presence of inhibitor considered the same time interval as in the absence of HPA. The addition of the inhibitor was after 5.5 hours of exposure in aerated solution, whereas for the de-aerated solution the addition of the inhibitor was after 1.5 hours of exposure. The electrochemical equipment was a Solartron interface 1287 connected to a frequency response analyzer 1260 and controlled by Zplot software.

\section{Impedance Analysis}

The Software ZView 3.1 (Scribner Associates) was used for EIS experimental analysis. The impedance spectra were modeled by fitting the experimental data with the Zview fitting/simulation application with 100 maximum iterations in the calculus modulus.

Table 1. Chemical Composition of 1018 Carbon Steels (Balance Fe)

\begin{tabular}{|c|c|c|c|c|c|c|c|c|c|c|}
\hline $\mathbf{A l}$ & $\mathbf{A s}$ & $\mathbf{C}$ & $\mathbf{C o}$ & $\mathbf{C r}$ & $\mathbf{C u}$ & $\mathbf{M n}$ & $\mathbf{M o}$ & $\mathbf{N b}$ & $\mathbf{N i}$ & $\mathbf{P}$ \\
\hline \hline 0.001 & 0.007 & 0.160 & 0.010 & 0.063 & 0.250 & 0.790 & 0.020 & 0.006 & 0.078 & 0.008 \\
\hline $\mathbf{S}$ & $\mathbf{S b}$ & $\mathbf{S i}$ & $\mathbf{S n}$ & $\mathbf{T i}$ & $\mathbf{V}$ & $\mathbf{Z r}$ & & & \\
\hline \hline 0.029 & 0.011 & 0.250 & 0.017 & $<0.001$ & 0.001 & 0.004 & & & \\
\hline
\end{tabular}




\section{Surface Analysis}

High-definition characterization and analysis was performed by Environmental Scanning Electron Microscopy (ESEM) and energy dispersive spectroscopy (EDS) techniques, respectively. The carbon steel samples were characterized at 40 and/or 90 hours of exposure to scaling solution. The microscope was an XL30 ESEM-Phillips, a gas secondary electrons detector (GSE) was used for environmental mode (low vacuum). X-Ray analysis was performed in energy dispersive X-ray analysis system D8 Advance-Bruker Instruments with radiation of $\mathrm{Cu} \mathrm{Ka}$ at $35 \mathrm{kV}$ and $30 \mathrm{~mA}$.

\section{RESULTS AND DISCUSSION}

\section{Open Circuit Potential}

The evolution of the open circuit potential (OCP) measurements for the steel-scaling solutions at $30^{\circ} \mathrm{C}$ is displayed in Fig. (3). The plot shows the transients of OCP at $\mathrm{pH}$ of 8.1 during 90 hours of exposure. The interfacial reactions lead to the formation of $\mathrm{Fe}_{2} \mathrm{O}_{3}$ by considering the $\mathrm{pH}$ and $\mathrm{OCP}$ magnitudes in aerated solutions [23, 24]. The continuous evolution of OCP to positive magnitudes for aerated solution in the absence of HPA in Fig. (3c) is attributed to the presence of the passivation layer at the surface. The HPA addition to the aerated-scaling solution in Fig. (3d) shifted the OCP magnitude to more positive value $(-0.58 \mathrm{~V}$ vs SCE). This latter magnitude demonstrated different properties of the corrosion products at the interface. The formation of iron and phosphorous-based precipitation products is feasible due to the electrolyte homogeneous reactions and the heterogeneous active-passive mechanisms in aerated solutions. Conversely, de-aerated solutions lead to different physicochemical properties for the corrosion products. Fig. (3a) illustrates the OCP in the absence of HPA, this magnitude oscillated near $-0.8 \mathrm{~V}$ vs SCE, the formation of more noble corrosion products with different physicochemical properties resulted in higher OCP magnitudes than aerated solutions. The addition of HPA to de-aerated solution after 1.5 hours of exposure changed the OCP as illustrated in Fig (3b). In both cases (aerated and de-aerated), the HPA addition modified the OCP by $\sim 100 \mathrm{mV}$, this is due to the physical characteristics of the phosphorous-based layer formed. However the control mechanism is different due to the oxygen content. The formation and accumulation of the corrosion products influenced the interfacial mechanisms. The dissolution process is the sum of the anodic and cathodic reactions, this latter is assumed to be the oxygen reduction reaction and considered by many authors as the step control process for scaling solutions at high $\mathrm{pH}[8,9]$.

\section{Impedance Evolution of Electrode-Scaling Aerated Solution}

Fig. (4) shows the impedance evolution of the 1018 steel sample exposed to aerated cooling water at $30^{\circ} \mathrm{C}$. The first six hours of exposure in Fig. (4a) displays two defined semicircles with IR correction. The loop presented at low frequencies (LF) is associated with the diffusion of oxygen. The second loop displayed at medium (MF) and high frequencies (HF) is attributed to the charge transfer resistance, which is associated with the oxygen reduction reaction. Fig. (4b) shows the impedance signal evolution at longer exposure times, where one additional small loop at high frequencies
(HF) represents the pore resistance of the corrosion products layer. The interface at early exposure time $(\leq 6 \mathrm{~h})$ represents the mass transfer-active control process influenced by the heterogeneous precipitation of the passive layer. The OCP magnitudes in Fig (3c) at early exposure corroborates the interfacial process transition showed at LF in the Nyquist representation. The impedance signature at longer exposure time $(\geq 10 \mathrm{~h})$ resulted in the appearance of a third loop at HF; this latter defined the evolution of the physical characteristics of the porous layer. Devos et al. [25] reported the impedance evolution of gold-chromium coating surface exposed in scaling conditions; the $\mathrm{CaCO}_{3}$ precipitation under hydrodynamic controlled conditions lead to the diffusion control process, they presented two contributions at the interface at different exposure times, one associated to the porous scaling layer and other to the oxygen mass transfer process. In this work, two processes (charge and mass transfer) influenced the impedance evolution at the interface driven by the oxygen diffusion and its reduction reaction. The third contribution in the impedance signature resulted from the evolution of the porous layer.

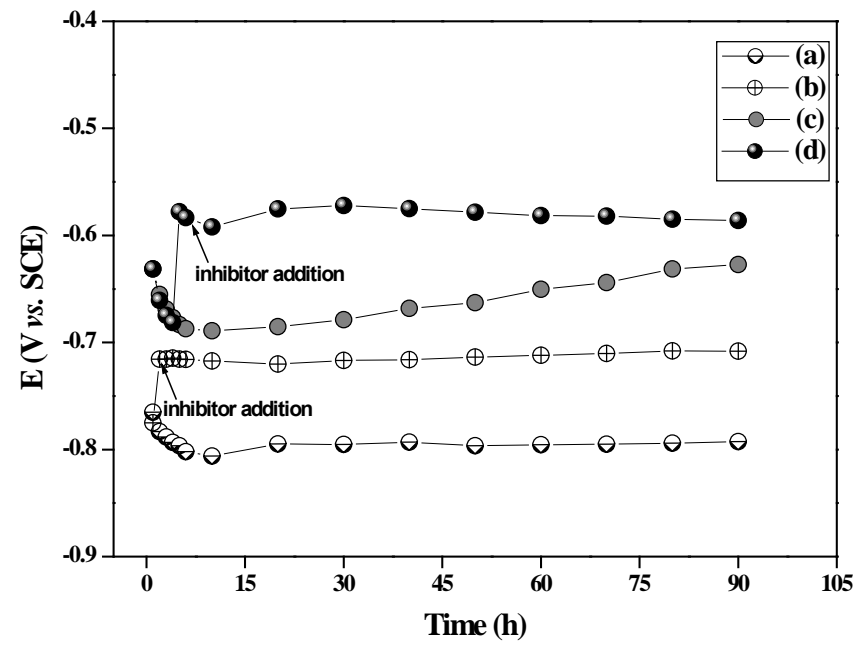

Fig. (3). Open circuit potential monitored at (a) absence of $\mathrm{O}_{2}$ and no inhibitor, (b) absence of $\mathrm{O}_{2}$ and inhibitor addition, (c) presence of $\mathrm{O}_{2}$ and no inhibitor, (d) presence of $\mathrm{O}_{2}$ and inhibitor addition.

Fig. (5a) shows the ESEM surface analysis of the steel sample after 40 hours of exposure in aerated solution. The formation of high dense corrosion products are mainly $\mathrm{CaCO}_{3}$ (calcite) and $\mathrm{Fe}_{2} \mathrm{O}_{3}$ and (hematite) as illustrated in the XRD analysis in Fig. (5b), however the ESEM shows smalluncovered sites existed within the porous of the layer representing sites for potential active sites.

Fig. (6) represents the electrical circuit analog describing the impedance evolution of the steel-aerated electrolyte at longer exposure time $(\geq 10 \mathrm{~h})$. The electrical elements represent the steel-scale solution interface under steady state conditions. The passive elements at HF represent the resistance of the pore layer $(\mathrm{Rp})$ and the pseudo-capacitance of the film (Qp) formed by the corrosion products; the MF is described by the charge transfer resistance $\left(\mathrm{R}_{\mathrm{O} 2}\right)$ due to the cathodic reaction and the constant phase element associated with the double layer capacitance $\left(\mathrm{Q}_{\mathrm{D}}\right)$. The $\mathrm{Rw}$ and $\mathrm{Qw}$ represent the elements characterizing the mass transfer of oxygen at LF. Marin et al. [26] represented the porous layer surface and the pseudo-capacitance with two time constants due to the corro- 
(a)

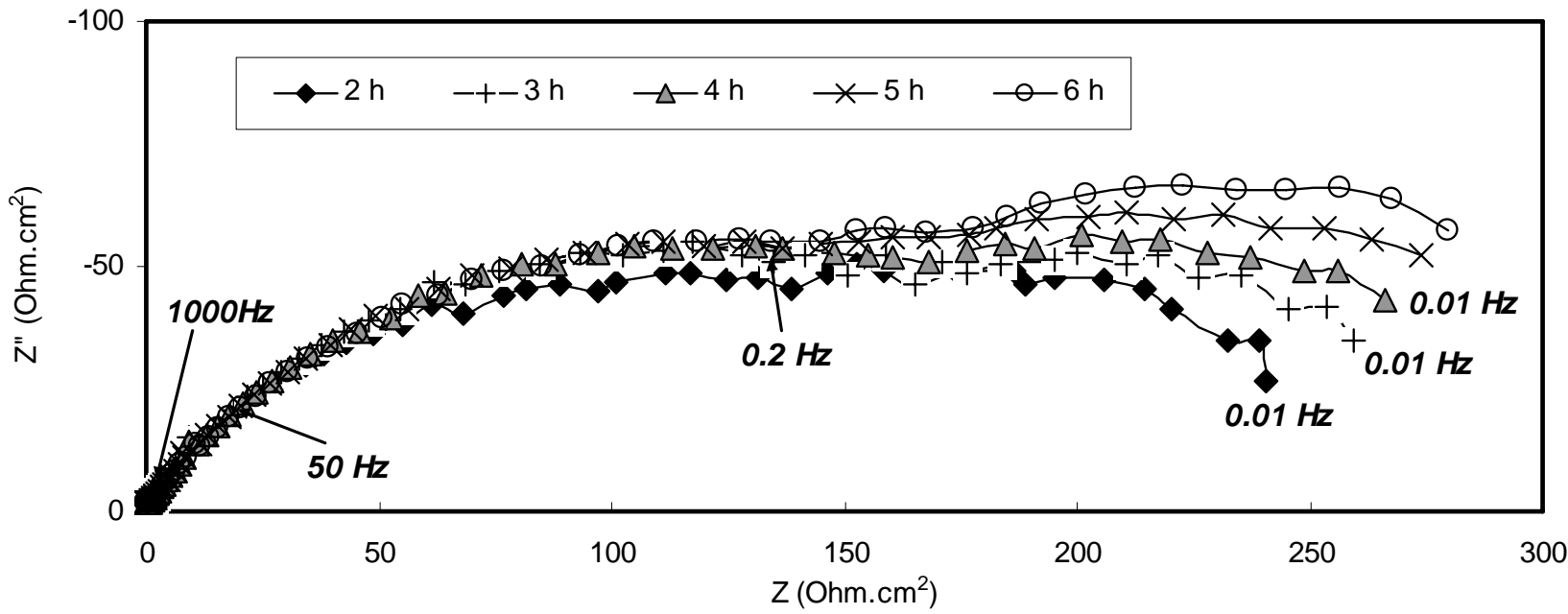

(b)

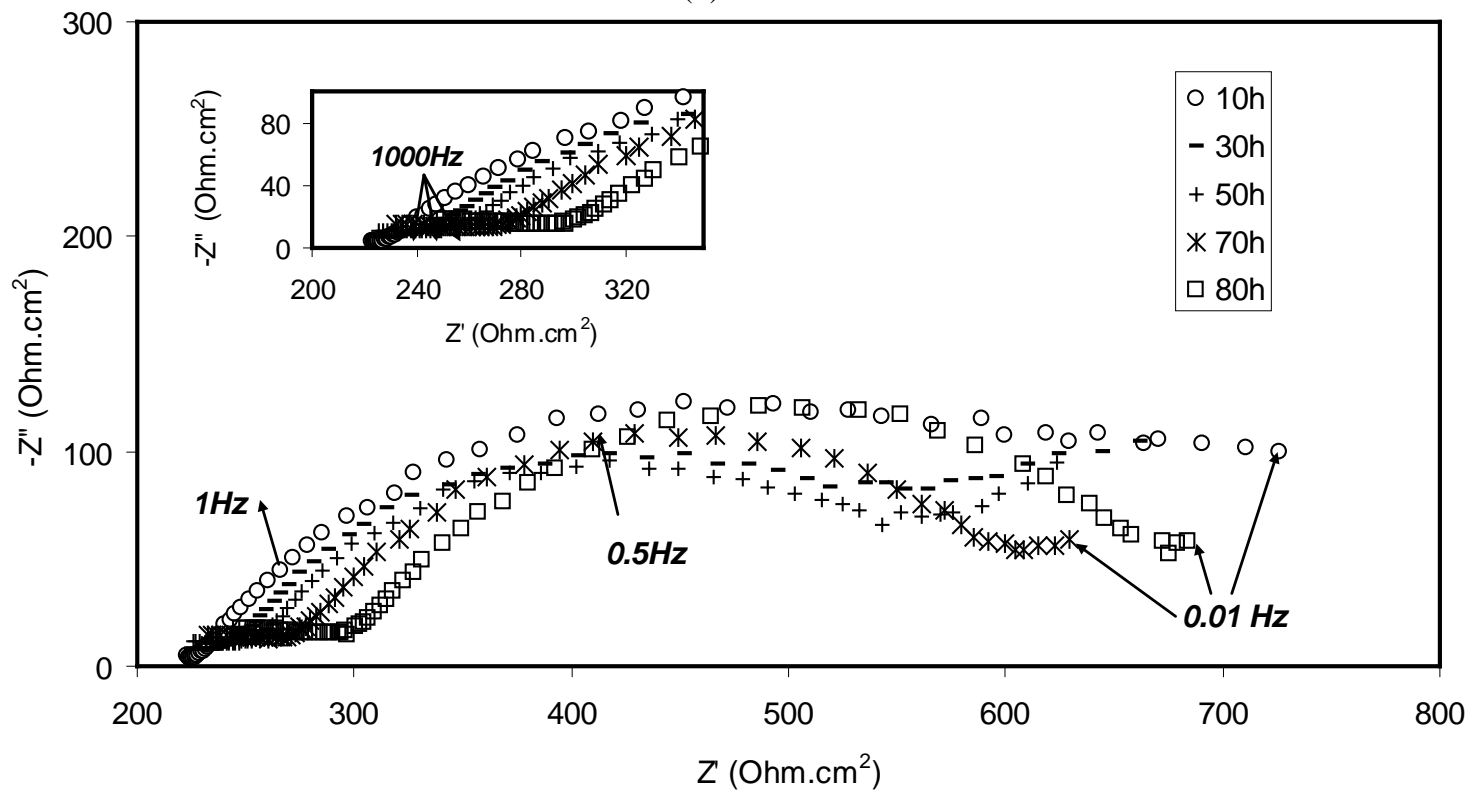

Fig. (4). Nyquist diagram of 1018 steel in cooling water system and slow rotation rate in aerated scaling solution: (a) IR correction for 6 hours of exposure, (b) No IR correction between 10 and 80 hours of exposure.

sion products formed at interface electrode-layer in scaling solution and mass transfer process in hydrodynamic controlled conditions. Here, an additional process appears at MF represented with the semicircle shape and simulated with a resistance, $\mathrm{R}_{\mathrm{O} 2}$ due to the oxygen reduction reaction in parallel with a constant phase element (CPE). The CPE is associated with the distribution properties of a pseudo-capacitance for double layer, $\mathrm{Q}_{\mathrm{D}}$ at MF; the porous capacitance, $\mathrm{Qp}$ at $\mathrm{HF}$; and $\mathrm{Qw}$ as the mass transfer distribution at LF. $\mathrm{Z}_{\mathrm{CPE}}$ follows the general expression (1) [25]:

$$
Z_{C P E}=\frac{1}{Q(j \omega)^{n}}
$$

where $Q$ is the pseudo-capacitance, and " $n$ " is a normalized constant in the range of $0<\mathrm{n}<1$.

The impedance distribution for the mechanisms described at different frequency intervals are simulated with constant phase element in the proposed equivalent circuit. The logarithm of the imaginary impedance in the absence of oxygen was plotted with the logarithm of the high, medium and low frequency; the magnitude of the slopes justifies the use of the CPE in the equivalent circuit [27].

Table 2 represents the evolution of passive elements resulted after fitting the circuit analog proposed in Fig. (6) with experimental results for aerated solution with no HPA. The passive elements were fitted on a minimization of nonlinear sum-square error; a reasonable fit was established by admitting 5\% error for each element in the equivalent circuit during the simulation/fitting process. The $\mathrm{R}_{\mathrm{p}}$ increases with time ranging from 111 to $244 \mathrm{Ohm} \mathrm{cm}^{2}$. $\mathrm{R}_{\mathrm{p}}$ magnitude associates the pore resistance of the layer. The magnitude is proportional to the surface coverage of the corrosion products at the surface as previously reported [25] for scaling solutions. The $\mathrm{R}_{\mathrm{O} 2}$ magnitude associated with the cathodic reaction shows no significant change with time ranging from 461 to $417 \mathrm{Ohm} \mathrm{cm}^{2}$. Diard [28] described the transition between active to mass transfer state due to the highpolarization conditions towards the oxygen reaction in the 
(a)

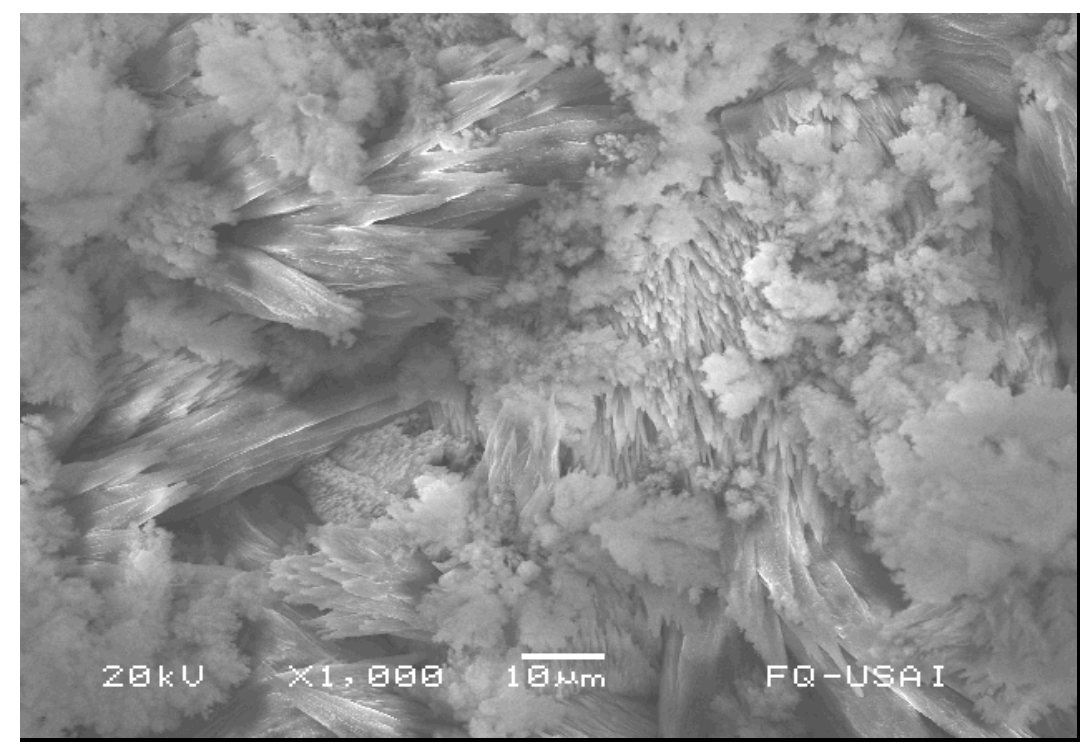

(b)

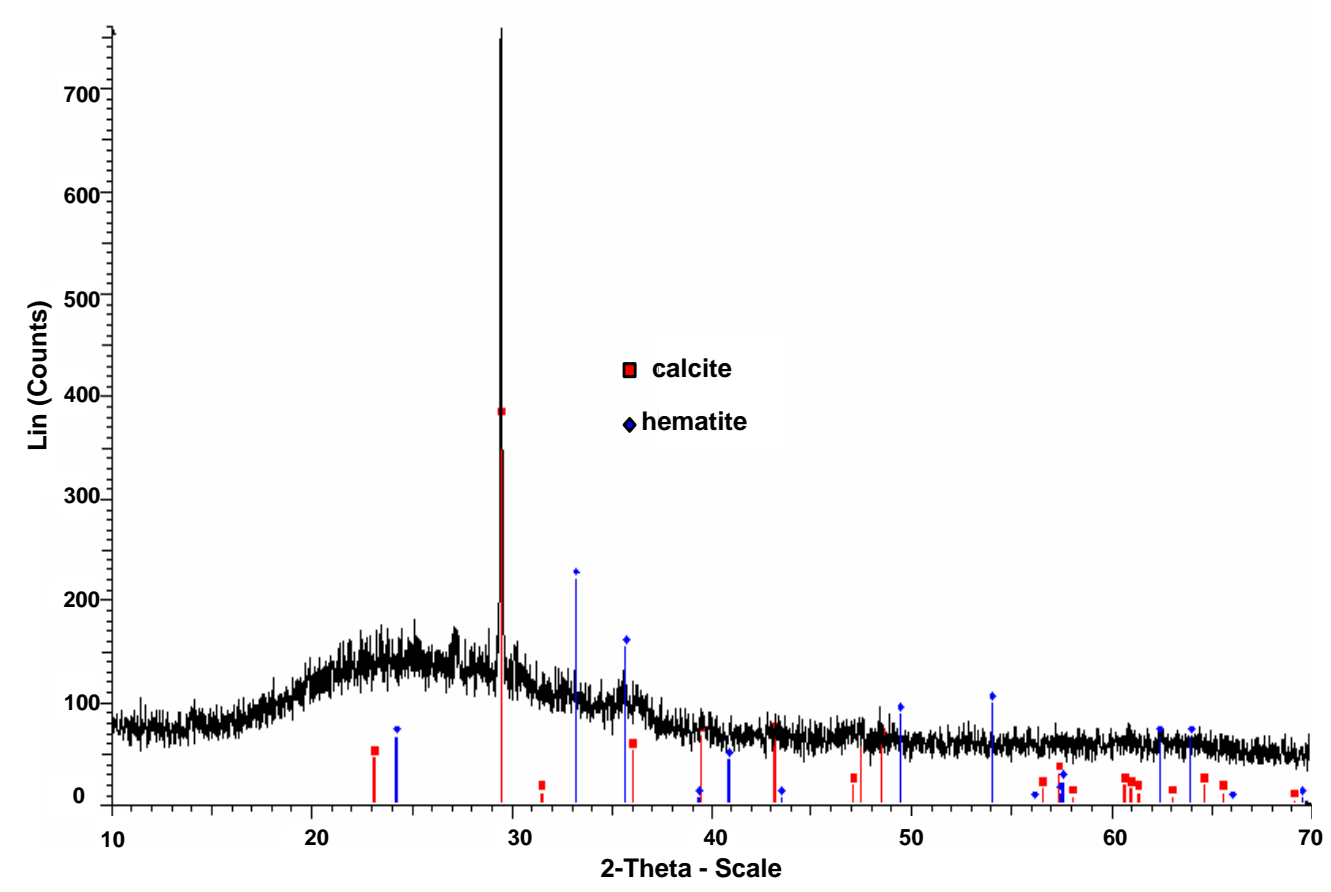

Fig. (5). (a) ESEM analysis at 1000x of the sample after 40 hours of exposition in aerated solution and no inhibitor. (b) XRD analysis of the sample after 40 hours of exposure in aerated solution and no inhibitor.

scaling system where the diffusion control is the predominant process. In this work, the interfacial evolution close to open circuit potential maintained the $\mathrm{R}_{\mathrm{O} 2}$ magnitude with no significant changes and the active-mass transfer mix process. The Rw magnitude characterizes the mass transfer process and the value fluctuates from 30 to $184 \mathrm{Ohm} \mathrm{cm}^{2}$. The hydrodynamic conditions influence the existence of a mix control process (active -mass transfer) at the interface. The pseudo-capacitance magnitude describing the double layer, $\mathrm{Q}_{\mathrm{D}}$ is displayed in Table 2. The $\mathrm{Q}_{\mathrm{D}}$ magnitudes are in the order of magnitude characteristic of similar scaling systems $[25,26]$ increasing from 16 to $94\left(\mu \mathrm{F} \mathrm{m}^{-2} \mathrm{~s} \mathrm{n}^{-1}\right)$, this latter is due to the higher conductivity influenced by the $\mathrm{CaCO}_{3}$ accumulation. The magnitudes for the pseudo-capacitance associated with the porous layer, $\mathrm{Q}_{\mathrm{p}}$ is calculated as $10(\mathrm{pF}$ $\left.\mathrm{m}^{-2} \mathrm{~s} \mathrm{n}^{-1}\right)$, this latter magnitude is influenced by the porous morphology of the precipitated layer $\left(\mathrm{Fe}_{2} \mathrm{O}_{3}+\mathrm{CaCO}_{3}\right)$ and close to the magnitude reported for scaling solutions precipitated at gold and chromium coating surface of 180pF [25]. 


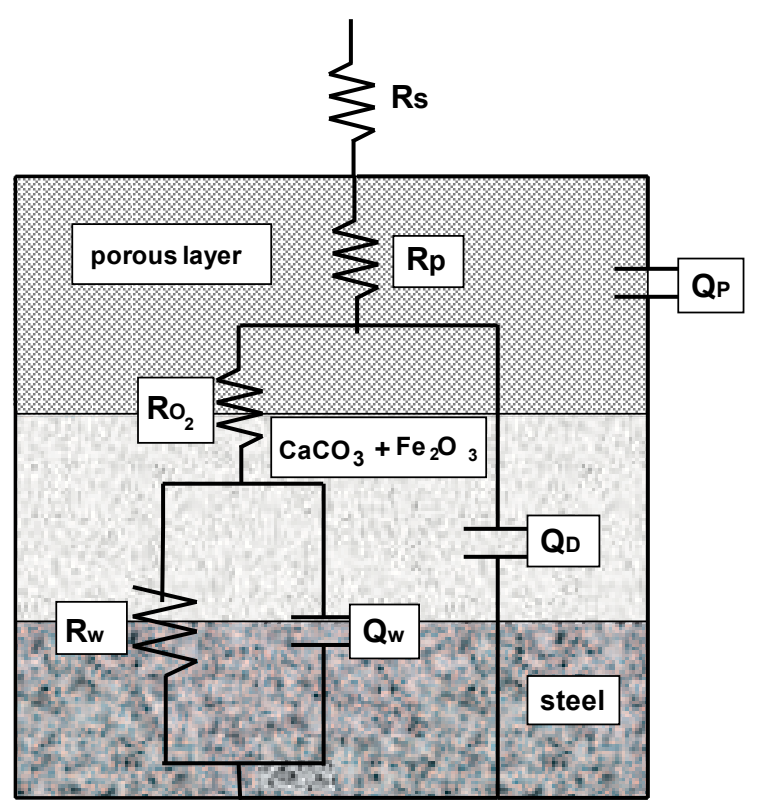

Fig. (6) Equivalent circuit for a 1018 carbon steel sample exposed to scaling in aerated solution at $30^{\circ} \mathrm{C}$.

Table 2. Equivalent Circuit Element Fitting Parameters for Aerated Solution at $30^{\circ} \mathrm{C}$

\begin{tabular}{|c|c|c|c|c|}
\hline $\mathbf{t}(\mathbf{h})$ & $\begin{array}{c}\mathbf{R}_{\mathbf{p}} \\
\left(\mathbf{O h m} \mathbf{~ c m}^{2}\right)\end{array}$ & $\begin{array}{c}\mathbf{Q}_{\mathbf{D}} \\
\left(\boldsymbol{\mu} \mathbf{F} \mathbf{~ m}^{-2} \mathbf{s ~ n}^{-1}\right)\end{array}$ & $\begin{array}{c}\mathbf{R}_{\mathbf{O} 2} \\
\left(\mathbf{O h m} \mathbf{~ m}^{2}\right)\end{array}$ & $\begin{array}{c}\mathbf{R w} \\
\left(\mathbf{O h m} \mathbf{~ c m}^{2}\right)\end{array}$ \\
\hline \hline 10 & 111 & 16 & 461 & 184 \\
\hline 20 & 129 & 26 & 406 & 172 \\
\hline 30 & 116 & 32 & 511 & 214 \\
\hline 40 & 126 & 43 & 546 & 236 \\
\hline 50 & 108 & 62 & 371 & 247 \\
\hline 60 & 107 & 66 & 370 & 167 \\
\hline 70 & 150 & 86 & 371 & 81 \\
\hline 80 & 136 & 83 & 408 & 52 \\
\hline 90 & 244 & 94 & 417 & 30 \\
\hline
\end{tabular}

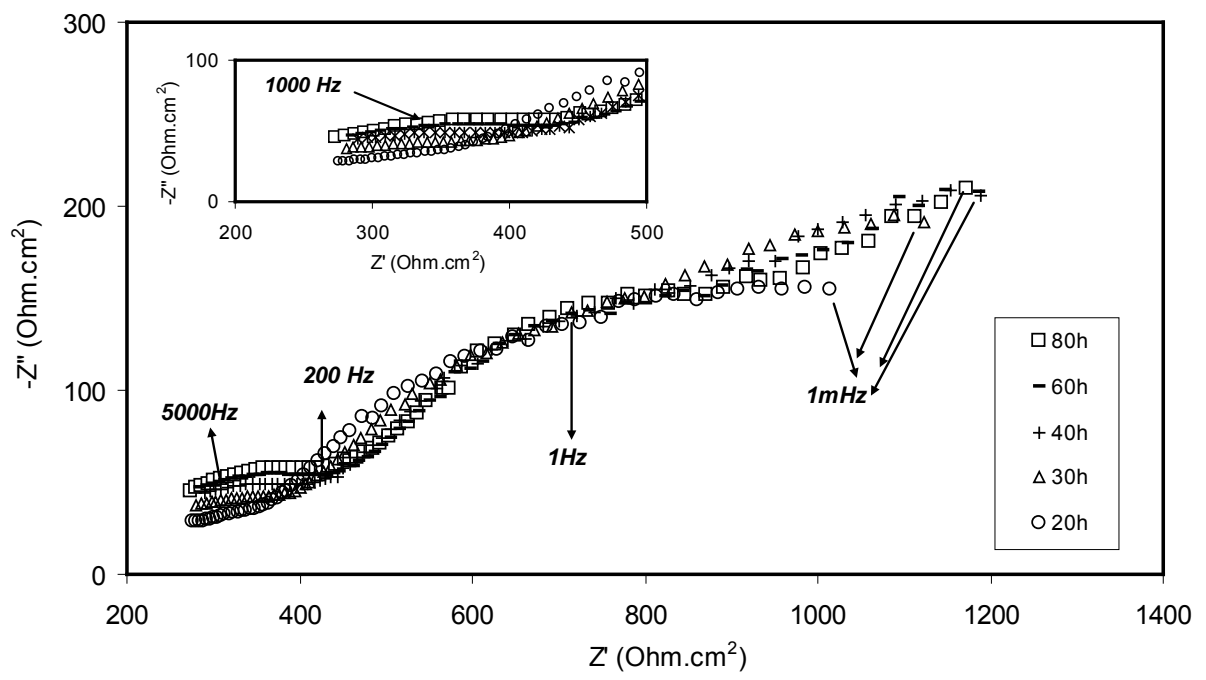

Fig. (7). Nyquist diagram of 1018 steel in cooling water system and slow rotation rate in presence of inhibitor during 10 to 80 hours of exposure, no IR correction.

\section{Impedance Evolution of Electrode-Scaling Aerated Solution with Inhibitor Addition}

The evolution of impedance following the addition of the HPA shows a loop at HF after 10 hours of exposure as displayed in Fig. (7). The HF response is associated with the pores of the layer formed at the interface. The addition of the HPA after five hours of exposure to aerated solution formed and stabilized the OCP magnitudes as displayed in Fig. (3d). During early exposure $(\leq 6 \mathrm{~h})$, the inhibitor behaves as an anodic inhibitor shifting the OCP toward more noble potentials as illustrated in Fig. (3d). After 10 hours of exposure, the inhibitor behaves as a mixed inhibitor. It stabilizes the corrosion products, which influences the impedance at HF due to formation-accumulation of the corrosion products at the surface. The 1,2-hydroxyphosphonoacetate group formed the phosphorous-based complexes by reacting with the calcium ions, and the iron oxide layer formed initially. The second loop at MF is attributed to the charge transfer process describing the reduction of oxygen. The LF response represents mass transfer process of the oxygen.

The ESEM surface analysis in Fig. (8a) shows the presence of corrosion products following HPA addition. Fig. (8b) displays the EDS analysis of the sample surface layer indicating a mixture of phosphorous, calcium, iron and oxygen products after $90 \mathrm{~h}$ of exposure. The formation of the phosphorous-based layer is attributed to the complexation process of the HPA with calcium ions as previously described [29]. Hydroxyphosphonoacetate ions sequestrated and reduced the effective $\mathrm{Ca}^{2+}$ concentration in the scaling solution by forming a complex phosphorous-based product. Shan and Jijian [30] reported the mechanism for complexation of $\mathrm{Ca}^{2+}$ in presence of phosphate compounds due to the presence of the P-O bonds. The mechanism includes two different paths for the homogeneous reaction: the first path assumed that four phosphorous of polyphosphate ion were needed to bond one $\mathrm{Ca}^{2+}$ in an oxygen-calcium ratio of $4: 1$. In the second path, only one atom of oxygen participated in the bonding, which derived a 2:1 oxygen-calcium ratio. A similar mechanism, equivalent to the second path is assumed in this work. Fig. (9) represents the structural distribution at the interface following the inhibitor reaction with the protec- 


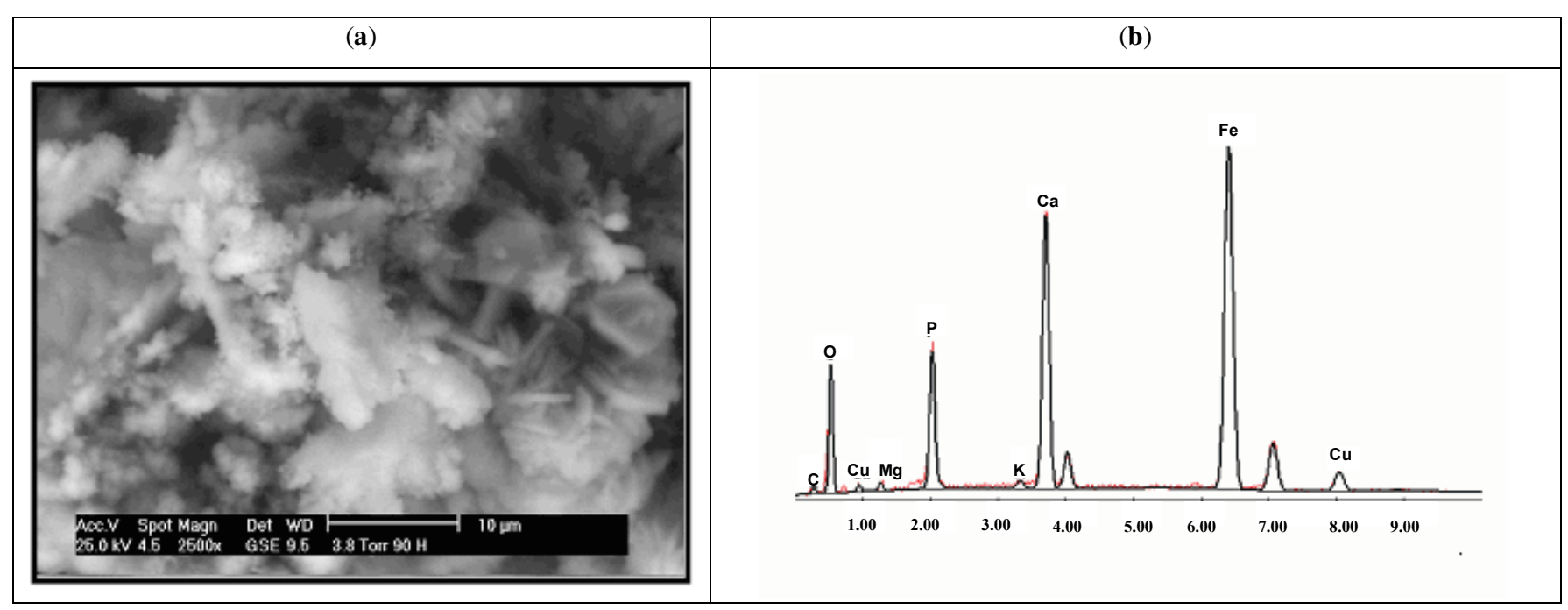

Fig. (8). ESEM and EDS analysis for the sample at 90 hours of immersion in aerated solution: (a) ESEM image at 2500x with addition of inhibitor, (b) EDS analysis corresponding to the previous Fig. (8a).

tive mix layer $\left(\mathrm{Fe}_{2} \mathrm{O}_{3}+\mathrm{CaCO}_{3}\right)$, previously described via calcium/hydroxyphosphonoacetic complexation [31]. The electrical analog representing this interface is equivalent to the previous case represented in Fig. (6). The resistances $R_{p i}$, $R_{\mathrm{O} 2 \mathrm{i}}$ and $\mathrm{R}_{\mathrm{wi}}$ represent the resistances of the corrosion product layer, charge transfer and oxygen diffusion respectively. The constant phase elements $\mathrm{Q}_{\mathrm{pi}}, \mathrm{Q}_{\mathrm{Di}}$ and $\mathrm{Qwi}$, represent the film capacitance, double layer, and mass transfer respectively in the presence of inhibitor. steel-scaling solution in presence of HPA. The $\mathrm{R}_{\mathrm{pi}}$ (pore layer resistance) magnitude increases with time, this latter due to the formation and accumulation of the phosphorus layer. The charge transfer resistance, $\mathrm{R}_{\mathrm{O} 2 \mathrm{i}}$ also increases with time. The magnitude ranges from 406 to $570 \mathrm{Ohm} \mathrm{cm}^{2}$; the effect is proportional to the phosphorous-based compounds and corrosion products accumulation at the surface. The magnitude of the parameter $\mathrm{Q}_{\mathrm{Di}}$ increases with time ranging from 0.9 to $7.7\left(\mu \mathrm{F} \mathrm{m}^{-2} \mathrm{~s} \mathrm{n}^{-1}\right)$. This pseudo-capacitance mag-

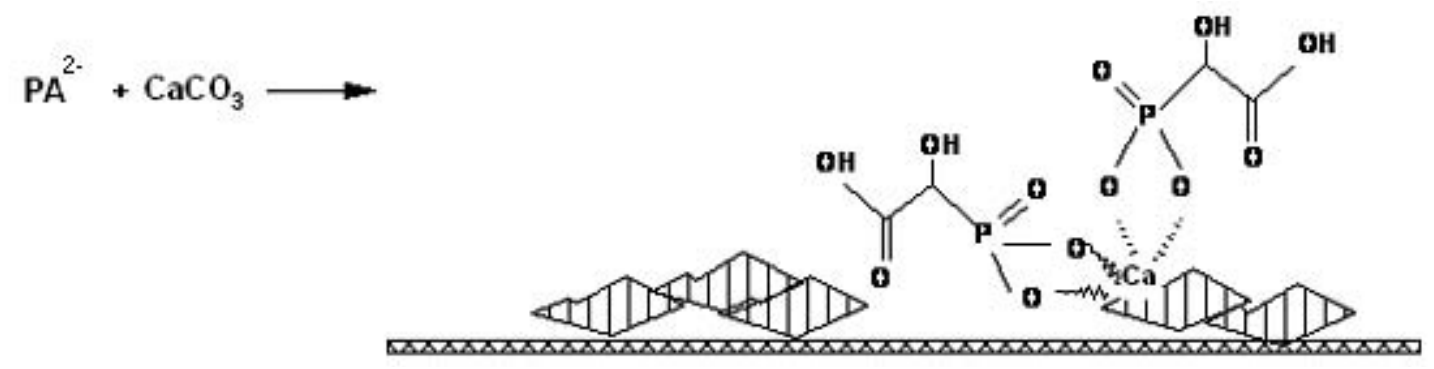

Fig. (9). Sequestration mechanism for the Ca by the addition of HPA in scaling solution at $30^{\circ} \mathrm{C}$.

Table 3 displays the evolution of the fitted experimental results associated with the interfacial elements $(>10 \mathrm{~h})$ of the nitude for the double layer is same order of magnitude as reported by Marin et al. [26]. The magnitude increases with

Table 3. Equivalent Circuit Element Fitting Parameters for Aerated Solutions with HPA Addition at $30^{\circ} \mathrm{C}$

\begin{tabular}{|c|c|c|c|c|c|}
\hline $\mathbf{t}(\mathbf{h})$ & $\mathbf{R}_{\mathrm{pi}}\left(\mathrm{Ohm} \mathbf{c m}^{2}\right)$ & $\mathbf{Q}_{\mathrm{Di}}\left(\mu \mathbf{F} \mathbf{m}^{-2} \mathbf{s ~ n}^{-1}\right)$ & $\mathbf{R}_{\mathrm{O} 2 \mathrm{i}}\left(\mathrm{Ohm}-\mathrm{cm}^{2}\right)$ & $\mathbf{Q}_{w i}\left(\mu \mathbf{F ~ m}^{-2} \mathbf{s ~ n}^{-1}\right)$ & $\mathbf{R}_{\mathrm{wi}}\left(\mathrm{Ohm} \mathrm{\textrm {cm } ^ { 2 } )}\right.$ \\
\hline 10 & 151 & 0.94 & 405 & 88 & 151 \\
\hline 20 & 278 & 2.55 & 474 & 15 & 431 \\
\hline 30 & 281 & 1.73 & 448 & 25 & 717 \\
\hline 40 & 318 & 3.23 & 451 & 52 & 774 \\
\hline 50 & 355 & 5.65 & 423 & 25 & 921 \\
\hline 60 & 361 & 5.85 & 460 & 12 & 788 \\
\hline 70 & 399 & 6.37 & 513 & 50 & 680 \\
\hline 80 & 401 & 7.10 & 560 & 32 & 758 \\
\hline 90 & 426 & 7.79 & 559 & 44 & 700 \\
\hline
\end{tabular}




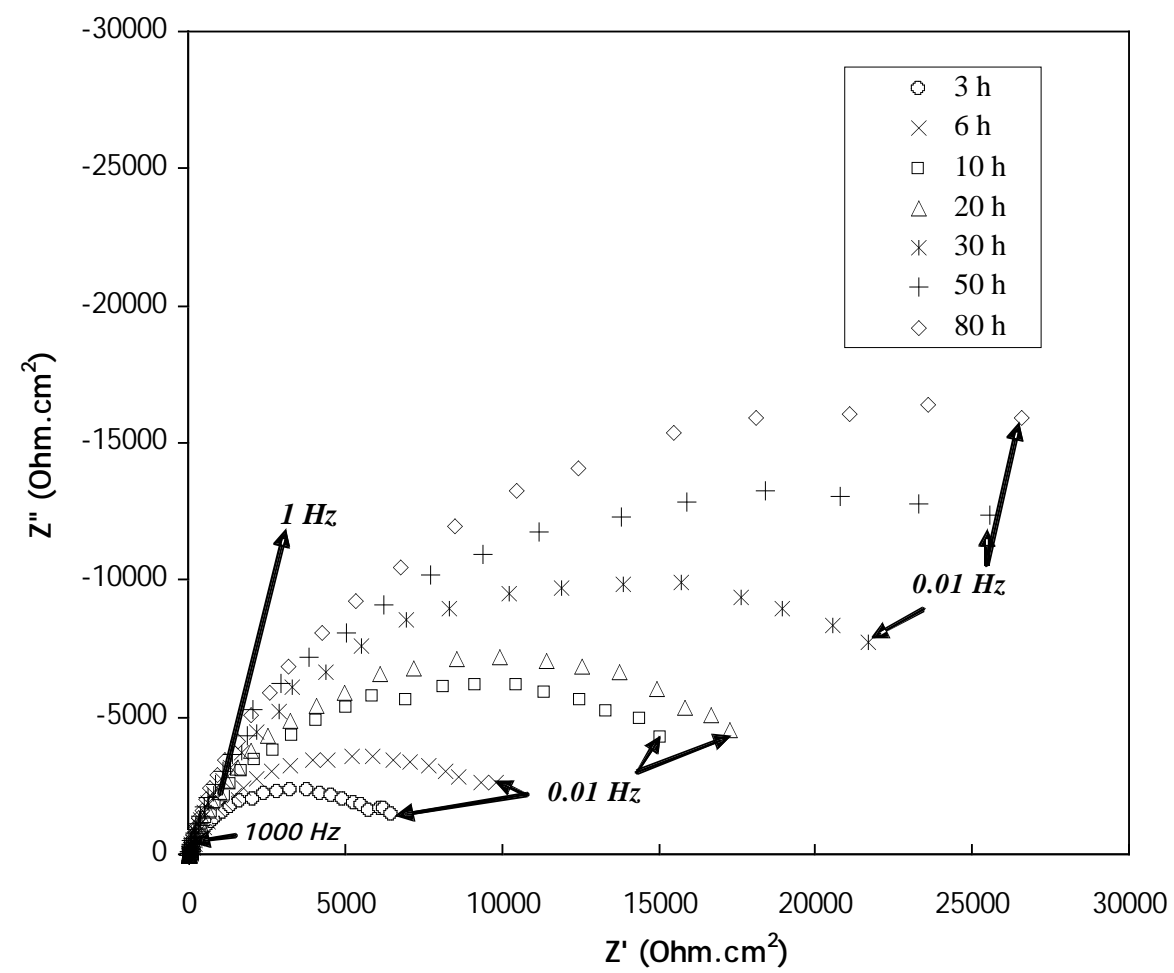

Fig. (10). Nyquist diagram for 1018 steel exposed in cooling water system and slow rotation rate in de-aerated scaling solution at $30^{\circ} \mathrm{C}$.

time due to the higher conductivity of the phosphorous layer following the addition of the HPA. However, $Q_{D i}$ is lower in magnitude than $\mathrm{Q}_{\mathrm{D}}$ due to denser precipitation of the phosphorus-based compounds formed in presence of HPA.

\section{Impedance Evolution of Electrode in De-Aerated Solution}

The oxygen content influences the dissolution of steel in scaling solution due to interfacial mechanisms as previously displayed in the OCP measurements. Fig. (10) shows the evolution of the impedance distribution in de-aerated solution after 3 hours. The results display one loop with finite amplitude characteristic of the charge transfer process. Fig. (3a) corroborates the feasibility of different corrosion products formation at the surface when de-aerated conditions are presented. We are assuming the formation of $\mathrm{Fe}(\mathrm{OH})_{2}$ and a mixture of $\mathrm{Fe}_{2} \mathrm{O}_{3}+\mathrm{Fe}_{3} \mathrm{O}_{4}$ due to de-aerated, $\mathrm{pH}$ and OCP conditions. The $\mathrm{Fe}_{3} \mathrm{O}_{4}$ formation mechanism has been described earlier by a two-step reaction for de-aerated solutions and oxidation of iron $[24,32]$ while the $\mathrm{Fe}_{2} \mathrm{O}_{3}$ has been described elsewhere [33]. The first step reaction in the formation of $\mathrm{Fe}_{3} \mathrm{O}_{4}$ includes the $\mathrm{Fe}(\mathrm{OH})_{2}$ as the product and the second step produces the magnetite by assuming the Schikkor reaction $[33,34]$ at the interface of the steel-electrolyte solutions. Conversely, we assumed the cathodic reaction in de-aerated solutions to be the water reduction.

The formation of corrosion product layer includes mainly the magnetite $\left(\mathrm{Fe}_{3} \mathrm{O}_{4}\right)$ precipitation with a mixture of $\mathrm{Fe}_{2} \mathrm{O}_{3}$ and $\mathrm{CaCO}_{3}$. The oxides mixture progressively forms a porous layer resulting in higher surface coverage area with time. The equivalent circuit associated with this process is represented in Fig. (11). The passive elements include the charge transfer resistance, $\mathrm{R}_{\mathrm{H} 2 \mathrm{O}}$ representing the water reduc- tion reaction in parallel with a pseudo-capacitance, whilst $\mathrm{Q}_{\text {no }}$ as the double layer. The magnitude represented by $\mathrm{R}_{\mathrm{H} 2 \mathrm{O}}$ increased continuously with time from $17283 \mathrm{Ohm} \mathrm{cm}^{2}$ to $41787 \mathrm{Ohm}^{2}$ as represented in Table 4. This continuous evolution in $\mathrm{R}_{\mathrm{H} 2 \mathrm{O}}$ is attributed to the formation of corrosion product layer (mainly $\mathrm{Fe}_{3} \mathrm{O}_{4}$ ) blocking the active sites available for the water reduction reaction. Schmuki et al. [35] found that the iron in borate solution at $\mathrm{pH}$ of 8.4 formed a stable $\mathrm{Fe}_{3} \mathrm{O}_{4}$ layer with no evidence of chemical dissolution in which the iron oxides $\left(\mathrm{Fe}_{3} \mathrm{O}_{4}+\mathrm{Fe}_{2} \mathrm{O}_{3}\right)$ react in solid state reaction instead, possibly to form $\mathrm{Fe}(\mathrm{OH})_{2}$. Devos et al. [25] could measure and correlate the impedance magnitudes with the coverage surface by using surface techniques for different coverage quantitative magnitudes. They determined that the charge transfer resistance of the cathodic reaction was proportional to the cover factor influenced by the scaling solution. In this case, the mixture of iron oxides influenced the $\mathrm{R}_{\mathrm{H} 2 \mathrm{O}}$ magnitude with time; the sites for reduction reaction were inversely proportional to the corrosion products distribution at the surface. The $\mathrm{Q}_{\mathrm{no}}$ magnitudes are characteristic of a double layer, as represented in Table $\mathbf{4}$ ranging from 17 to $35 \mu \mathrm{F} \mathrm{m}^{-2} \mathrm{~s} \mathrm{n}^{-1}$. This increment is attributed to the conductivity magnitude of the passive layer formed mainly by the $\mathrm{Fe}_{3} \mathrm{O}_{4}\left(0.2 \mathrm{ohm}^{-1} \mathrm{~cm}^{-1}\right)$ [36] within the mixture of iron oxide. The $n$ magnitude increases with time closer to the unit, this is due to the formation of a denser non-conductive layer compose of iron oxides.

\section{Impedance Evolution of Electrode in de-Aerated Solution with Inhibitor Addition}

Fig. (12) represents the impedance evolution of carbon steel in de-areated scaling solution in presence of HPA at longer times ( $\geq 2$ hours of exposure). The Nyquist plot shows 


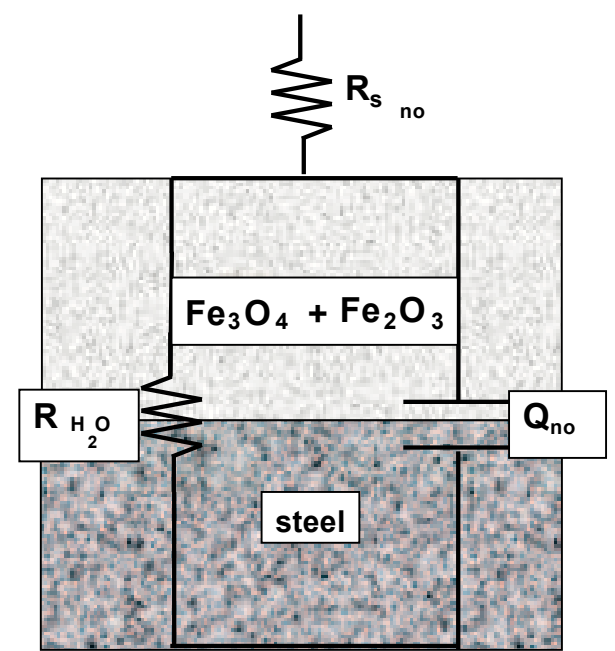

Fig. (11). Equivalent circuit passive element magnitudes for steelscaling de-aerated solution in absence of inhibitor at $30{ }^{\circ} \mathrm{C}$.

Table 4. Equivalent Circuit Passive Element Magnitudes for Steel- Scaling De-Aerated Solution in Absence of Inhibitor at $30^{\circ} \mathrm{C}$

\begin{tabular}{|c|c|c|c|}
\hline $\mathbf{t}(\mathbf{h})$ & $\mathbf{Q}_{\mathbf{n o}}\left(\boldsymbol{\mu} \mathbf{F} \mathbf{~ m}^{-\mathbf{2}} \mathbf{s ~ n}^{-\mathbf{1}}\right)$ & $\mathbf{n}_{\mathbf{O} 2}$ & $\mathbf{R}_{\mathbf{H} \mathbf{2}}\left(\mathbf{O h m} \mathbf{~ c m}^{2}\right)$ \\
\hline \hline 10 & 17 & 0.79 & 17283 \\
\hline 20 & 21 & 0.83 & 19019 \\
\hline 30 & 24 & 0.84 & 25719 \\
\hline 40 & 27 & 0.84 & 25291 \\
\hline 50 & 31 & 0.85 & 32757 \\
\hline 60 & 31 & 0.85 & 36458 \\
\hline 70 & 32 & 0.85 & 37422 \\
\hline 80 & 34 & 0.85 & 39494 \\
\hline 90 & 35 & 0.85 & 41787 \\
\hline
\end{tabular}

one capacitive loop where the magnitude of the diameter increases with time following the addition of HPA. The magnitude of the diameter is associated with the charge transfer reaction $\mathrm{R}_{\mathrm{H} 2 \mathrm{Oi}}$, this latter due to the water reduction reaction. The equivalent circuit describing this system is similar to de-aerated solution, where the electrical resistance, $\mathrm{R}_{\mathrm{H} 2 \mathrm{Oi}}$ and constant phase element, $\mathrm{Q}_{\text {noi }}$, are in parallel. The increment in $\mathrm{R}_{\mathrm{H} 2 \mathrm{Oi}}$ magnitude is attributed to the distribution and physical characteristics of corrosion products (mainly $\mathrm{Fe}_{3} \mathrm{O}_{4}$ ) that are precipitated at the surface following the complexation reaction. Sahoo et al. [37] reported the highdensity packing of the phosphonates with the $\mathrm{Fe}_{3} \mathrm{O}_{4}$ nanoparticles that influenced the porous density and complexation of the $\mathrm{Fe}_{3} \mathrm{O}_{4}$ layer. Moreover, Yee et al. [38] have observed phosphonate surface interactions with $\mathrm{Fe}^{3+}$ in functionalized $\mathrm{Fe}_{2} \mathrm{O}_{3}$ particles. The phosphorous-based compounds precipitated and covered the metallic surface continuously with the mixture of iron oxides. The surface image in Fig. (13a) shows the plate shape of the phosphorus-based compounds and the EDS in Fig. (13b) confirms the phosphorous content. The morphology of the plates blocked available spaces for the water reduction reaction at the interface. Therefore, the cathodic reaction becomes less predominant with time due to the denser layer precipitated in the active surface. The equivalent circuit analog used for this system is same as in Fig. (11), but in this system $\mathrm{R}_{\mathrm{H} 2 \mathrm{Oi}}$ element associates the charge transfer reaction in parallel with a pseudo-capacitance $\mathrm{Q}_{\text {noi }}$ that characterized the double layer following the inhibitor addition. The de-aerated conditions influenced the formation of hydroxyphosphonate-based compounds from the precipitation of iron ions in such a way that two different bonding schemes between iron species from $\mathrm{Fe}_{3} \mathrm{O}_{4}$ with the hydroxyphosphonoacetate ion can exist. Grosseau et al. [39] have determined that $\mathrm{Fe}^{2+}$ and $\mathrm{Fe}^{3+}$ iron cations at low to moderate temperatures have influenced the formation of iron phosphate and they concluded that different forms of iron ions are able to react and form phosphorous-based compounds. In this case, the laminate geometry resulting from the reaction between the HPA with the iron oxides and calcium ions is distributed at the surface as displayed in Fig. (13a).

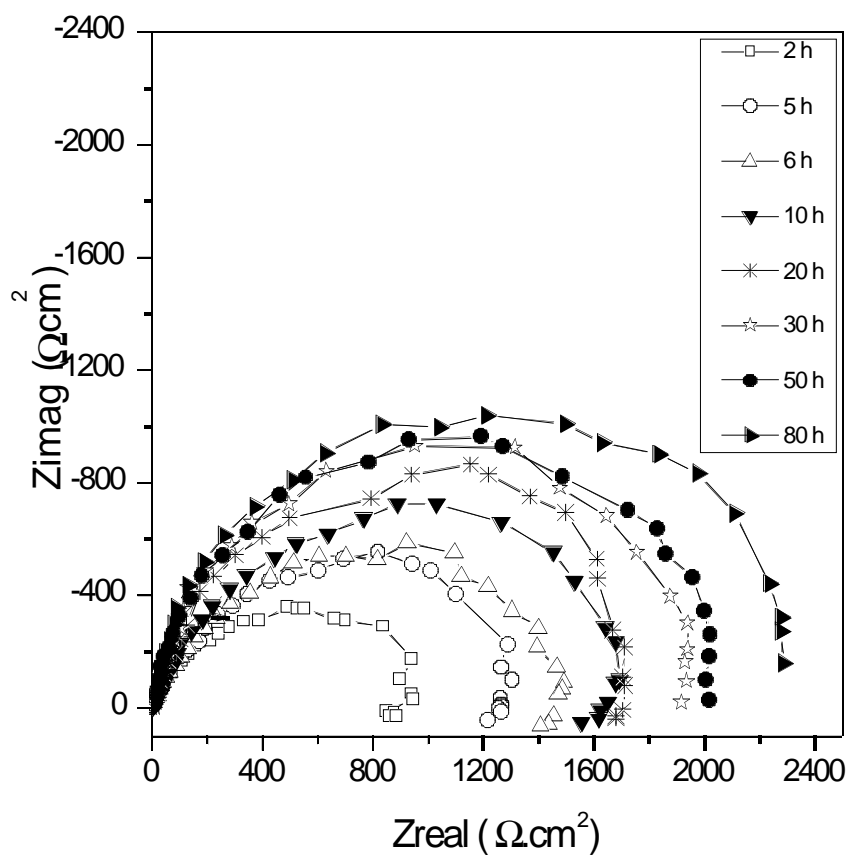

Fig. (12). Nyquist diagram for 1018 steel exposed in cooling water system and slow rotation rate in de-aerated scaling solution at $30^{\circ} \mathrm{C}$ in presence of HPA.

Table 5 shows the evolution of $\mathrm{Q}_{\text {noi }}$ magnitudes ranging from 65 to $286\left(\mu \mathrm{F} \mathrm{m}^{-2} \mathrm{~s} \mathrm{n}^{-1}\right)$ while the charge transfer resis-

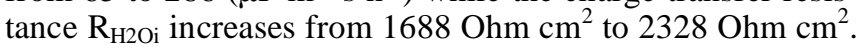
The formation of the mixed corrosion products influence the magnitude " $n$ " close to the unit, due to the formation of denser corrosion products. The iron oxide contributes to the laminate geometry and distribution of the precipitation of the phosphorous-based compounds. The distribution of the layers leaves un-coverage area for electrode-electrolyte interaction. The increment in the $\mathrm{Q}_{\text {noi }}$ magnitude associates the corrosion products mixture layer due to the conductive characteristics of the phosphorous-based compound with the magnetite $\left(\mathrm{Fe}_{3} \mathrm{O}_{4}\right)$. The $\mathrm{R}_{\mathrm{H} 2 \mathrm{Oi}}$ magnitude for de-aerated solution is one order of magnitude lower than the $\mathrm{R}_{\mathrm{O} 2 \mathrm{i}}$ magnitude for aerated electrolyte. This latter is attributed to the distribution of the corrosion products mixture precipitated at the 
(a)

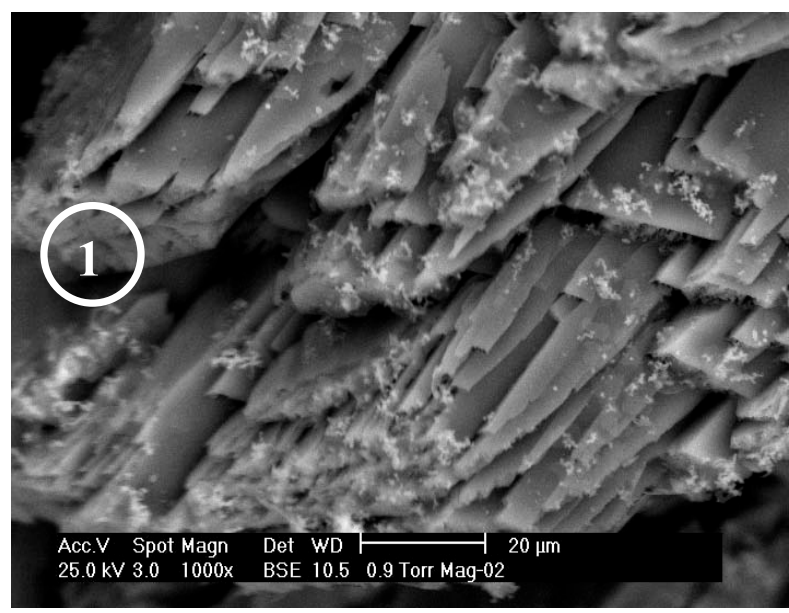

(b)

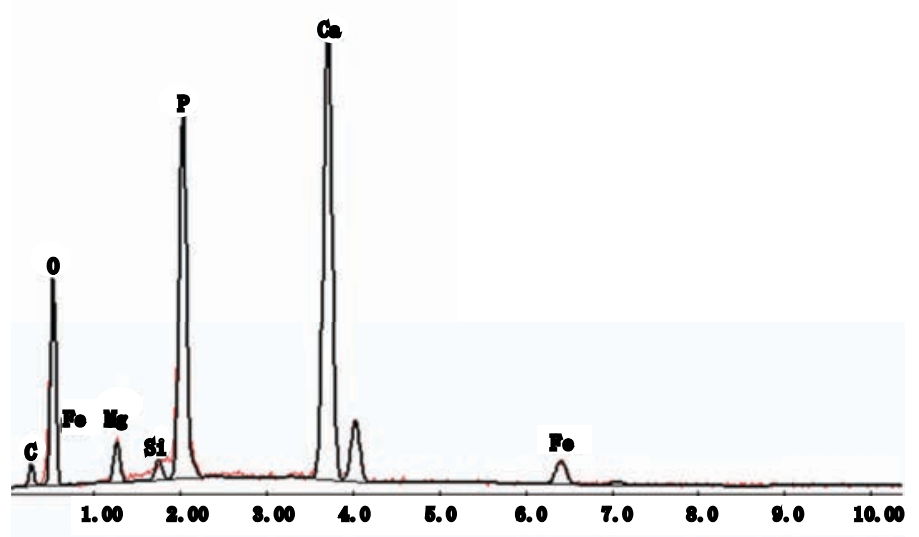

Fig. (13). ESEM and EDS analysis of the sample for 90 hours of immersion in de-aerated solution with addition of inhibitor. (a) ESEM image at 1000x, (b) EDS analysis corresponding to the point 1 showed in Fig. (13a).

interface. De-aerated electrolytes included iron oxide as magnetite $\left(\mathrm{Fe}_{3} \mathrm{O}_{4}\right)$ while aerated solution included higher amount of $\mathrm{Fe}_{2} \mathrm{O}_{3}$ and no presence of magnetite.

Table 5. Equivalent Circuit Passive Element Magnitudes for Steel-Scaling De-Aerated Solution in Presence of HPA at $30^{\circ} \mathrm{C}$

\begin{tabular}{|c|c|c|c|}
\hline $\mathbf{t}(\mathbf{h})$ & $\mathbf{Q}_{\text {noi }}\left(\mu \mathbf{F ~ m}^{-\mathbf{2}} \mathbf{s ~ n}^{-\mathbf{1}}\right)$ & $\mathbf{n}_{\mathbf{o i}}$ & $\mathbf{R}_{\mathbf{H} 2 \mathrm{Oi}}\left(\mathbf{O h m} \mathbf{c m}^{\mathbf{2}}\right)$ \\
\hline \hline 10 & 65 & 0.86 & 1688 \\
\hline 20 & 90 & 0.87 & 1832 \\
\hline 30 & 148 & 0.90 & 2021 \\
\hline 40 & 164 & 0.90 & 2090 \\
\hline 50 & 211 & 0.91 & 2094 \\
\hline 60 & 249 & 0.92 & 2047 \\
\hline 70 & 239 & 0.93 & 2295 \\
\hline 80 & 286 & 0.90 & 2395 \\
\hline 90 & 286 & 0.90 & 2328 \\
\hline
\end{tabular}

The influence of the variables added to the electrolyte resulted in different effectiveness of the inhibitiondissolution process. The impedance signature could reflect the differences according to the interfacial processes, such as the evolution of charge transfer magnitude Rct $\left(\mathbf{R}_{\mathbf{O 2}}, \mathbf{R}_{\mathbf{O 2} \text { i, }}\right.$ $\mathbf{R}_{\mathbf{H 2 O}}, \mathbf{R}_{\mathbf{H 2 O i}}$ ) in different scaling solutions. Wang et al. [40] calculated the inhibition effectiveness by expression (2):

$\%$ Eff $=\frac{\text { Rct, },_{i}-\text { Rct }_{,_{0}}}{R c t,{ }_{i}}$

where, Rct, ${ }_{i}$ is the charge transfer resistance with inhibitor environment ( $\mathbf{R}_{\mathbf{O 2 i}}, \mathbf{R}_{\mathbf{H 2 O}}, \mathbf{R}_{\mathbf{H 2 O i}}$ ), and $\mathrm{Rct}_{{ }_{0}}$ is the charge transfer in the control conditions $\left(\mathbf{R}_{\mathbf{O} 2}\right)$. Fig. (14) displays the effectiveness of inhibition process by assuming the charge transfer as the parameter comparable to the different conditions. The effectiveness of the inhibition process in deaerated conditions is higher than HPA addition conditions, the corrosion product formation (iron oxide layer) and the interfacial evolution described earlier contribute to the highest magnitude.

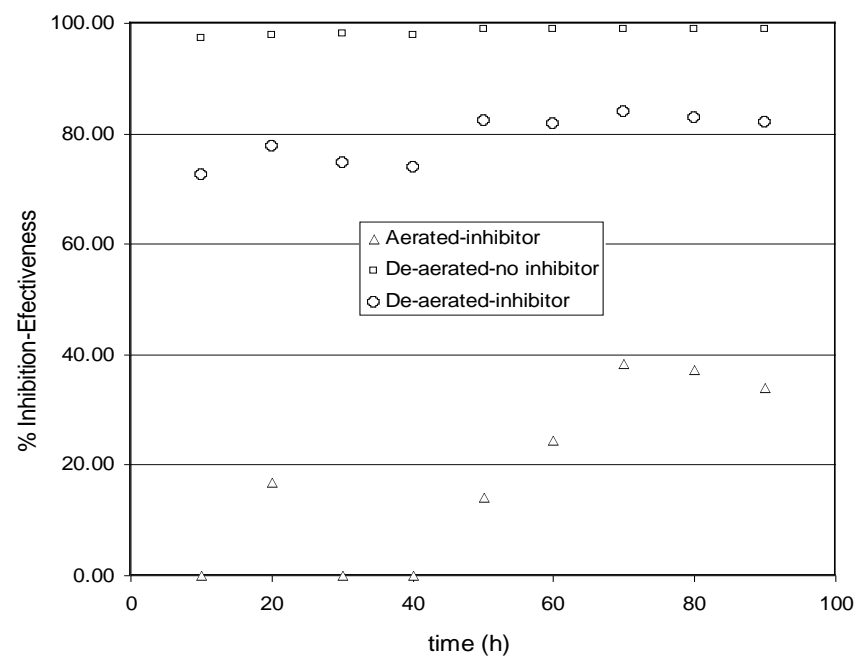

Fig. (14). Effectiveness of the inhibition mechanism at different exposure time.

\section{CONCLUSIONS}

The evolution of impedance characterized qualitatively (1) the oxygen content effect at the steel- electrolyte interface and (2) the influence in the inhibition dissolution mechanisms in the presence of HPA.

The impedance distribution in aerated scaling solutions and surface analysis corroborates the formation of a mixture of corrosion products (hematite and calcite) at the interface, and the influence of the active-mass transfer process. The sequestration of $\mathrm{Ca}$ ions by HPA and the precipitation of phosphorous-based compounds resulted in higher charge transfer magnitudes, therefore more stable and protective layer for inhibition effectiveness.

The formation of iron oxide mixture at lower oxygen content (de-aerated conditions) inhibits the dissolution process more efficiently than HPA addition for aerated solutions. 
Therefore, the lower oxygen content in solution suggests an alternative solution for corrosion control in scaling solutions. The addition of the HPA to de-aerated solution does not favor the stability of the phosphorous-based compounds due to the mechanisms existed at the interface and the morphology of the corrosion products.

\section{ACKNOWLEDGEMENT}

The authors acknowledge the assistance of Guillermina González Mancera at the UNAM Laboratory for SEM (Scanning Electron Microscopy) imaging.

\section{REFERENCES}

[1] Johnson WM. Practical Cooling Technology. Delmar Publishers: USA 1997; p. 553.

[2] Lichtenstein J. Water treatment for cooling systems. Mater Perform ProQuest Sci J 2004; 43(5): 62

[3] Choudhary SG. Monitor and control cooling water corrosion: corrosion coupons and online instruments help diagnose problems: maintenance and reliability. Hydrocarb Process 2004; 83(5): 55-64.

[4] Mueller E, Sikes CS, Little BJ. Peptide interactions with steel surfaces: inhibition of corrosion and calcium carbonate precipitation. Corros Sci 1993; 49(10): 829-35.

[5] Yang B, Reed PE, Morris JD. Inventors; Ondeo Nalco Company, assignee. Corrosion inhibitors for aqueous systems. United Stated Patent US 20036572789 B1 2003, June.

[6] Gopi D, Girija TC, Ramesh S, Rajeswari S. Studies on scaling and corrosion characteristics of ground water. Asian J Chem 2002; 14(34): 1729-36.

[7] Klepetsanis PG, Koutsoukos PG, Amjad Z. Calcium carbonate and calcium phosphate scale formation and inhibition at elevated temperature. In: Amjad Z, Ed. Advances in crystal growth inhibition technologies. Kluwer Academic/Plenum Publishers: New York 2000; pp. 139141.

[8] Marin-Cruz J, García-Figueroa E, Miranda-Hernandez M, González I. Electrochemical treatments for selective growth of different calcium carbonate allotropic forms on carbon steel. Water Res 2004; 38: 17383.

[9] Devos O, Gabrielli C, Tlili M, Tribollet B. Nucleation-growth process of scale electrodeposition. J Electrochem Soc 2003; 150(7): 494-501.

[10] Hernández R, Galicia M, Castaneda H, Zamudio L. Dissolution and inhibition mechanism of 1018 steel in simulated cooling water by adding phosphonoacetic acid compound under two flow conditions. ECS Trans 2006; 1(9): 223.

[11] Gabrielli C, Keddam M, Khalil A, Rosset R, Zidoune M. Study of calcium carbonate scales by electrochemical impedance spectroscopy. Electrochim Acta 1997; 42(8): 1207-18.

[12] Mansfeld F, Kendig MW, Lorenz WJ. Corrosion inhibition in neutral aerated media. J Electrochem Soc 1985; 132(2): 290-96.

[13] Lorenz WJ, Mansfeld F. Interface and interphase corrosion inhibition. Electrochim Acta 1986; 31(4): 467.

[14] Yu D, Pebere N, Dabosi F. An investigation of the corrosion of pure iron by electrochemical techniques and in situ observations. Corros Sci 1993; 34(1): 5 .

[15] Mosayebi B, Kazemeini M. Effect of phosphonate based corrosion inhibitors in a cooling water system. Br Corros J 2002; 37(3): 217.

[16] Boffardi PB, Schweitzer GW. Advances in the chemistry of alkaline cooling water treatment. Corrosion 1986; 86: 132.

[17] Rajendran S, Sridevi SP, Anthony N, John AA, Sundaravadivelu M. Corrosion behaviour of carbon steel in polyvinyl alcohol. Anti-Corros Method M 2005; 52(2): 102.

[18] Chen W, Diao LT, Yin XQ, Yi SJ, Mei P. Performance evaluation of imidazoline corrosion/scale inhibitor NY-HGA in produced water of Weizhou-12-1 offshore oil field. Oilfield Chem 2005; 22(2): 126.
[19] Meng Y, Wan L, Chen X, Chen G, Yang L, Wang J. Corrosion control in oil and gas production - fluids, chemicals, materials and more. Second SPE International Symposium on Oilfield Corrosion; Aberden, UK: Current Associates Inc 2005; pp. 15-25.

[20] Yntema S, De Boer P, Trompert RA, De Jonge RM, Van Gellekom. SPE-ICoTA Coiled Tubing and Well Intervention Conference and Exhibition 2006; pp. 105-116.

[21] Murthy Tata LN. A systematic approach to prevent internal corrosion of pipelines. Mater Perform 2007; 46 (12): 44

[22] Yang B, Reed PE, Morris JD, inventors; Ondeo Nalco Company, assignee. Corrosion inhibitors for aqueous systems. International Application Published Under The Patent Cooperation Treaty (PCT) WO 02/079105 2002 Oct.

[23] Martins JI, Nunes MC. Reconsidering differential aeration cells. Electrochim Acta 2006; 52(2): 552-59.

[24] Beverskog B, Puigdomenech I. Revised pourbaix diagrams for iron at 25-300 ${ }^{\circ} \mathrm{C}$. Corros Sci 1996; 38(12): 2121-35.

[25] Devos O, Gabrielli C, Tribollet B. Simultaneous EIS and in situ microscope observation on a partially blocked electrode application to scale electrodeposition. Electrochim Acta 2006; 51(8/9): 1413-22.

[26] Marın-Cruz J, Cabrera-Sierra R, Pech-Canul MA, Gonzalez I. EIS study on corrosion and scale processes and their inhibition in cooling system media. Electrochim Acta 2006; 51(8/9): 1847-54.

[27] Brug GJ, Van Den Eeden ALG, Sluyters-Rehbach M, Sluyters JH. The analysis of electrode impedances complicated by the presence of a constant phase element. J Electroanal Chem 1984; 176(1/2): 275-95.

[28] Diard JP, Hecker C. Experimental and theoretical study of impedance diagram of a redox system near to the diffusion plateau. J Electroanal Chem 1981; 121(C): 125.

[29] Uchtman VA. Structural investigations of calcium binding molecules. II. The crystal and molecular structures of calcium dihydrogen ethane1-hydroxy-1, 1-diphosphonate dihydrate, $\mathrm{CaC}\left(\mathrm{CH}_{3}\right)(\mathrm{OH})\left(\mathrm{PO}_{3} \mathrm{H}\right)_{2}$ $2 \mathrm{H}_{2} \mathrm{O}$; implications for polynuclear complex formation. J Phys Chem 1972; 76(9): 1304-10

[30] Shan W, Jijian C. Dissolution products of a phosphate glass scale inhibitor and its scale inhibition mechanism. Glass Technol 2001; 42 (4/5): 122-5.

[31] Neagle W. Hydroxy Phosphonoacetic Acid (HPA)-A mechanistic investigation of corrosion inhibition under cooling water conditions. Paper 568. Corrosion Nace. NACE International Publication Division: Houston, Texas 1991

[32] Davies DH, Burstein GT. Effects of bicarbonate on the corrosion and passivation of iron. Corrosion 1980; 36(8): 416.

[33] Schikorr G. On the reactions between iron, its hydroxides and water. $\mathrm{Z}$ Elektrochem 1929; 35: 65.

[34] Schikorr G. On iron (II)-hydroxide and a ferromagnetic iron(III)hydroxide. Anorg Allg Chem 1933;212(1): 33.

[35] Schmuki P, Virtanen S, Davenport AJ, Carissima M, Vitu J. In situ Xray absorption near-edge spectroscopic study of the cathodic reduction of artificial iron oxide passive films. J Electrochem Soc 1996; 143(2): 574.

[36] Guskos N, Papadopoulos GJ, Likodimos V, et al. Photoacoustic, EPR and electrical conductivity investigations of three synthetic mineral pigments: hematite, goethite and magnetite. Mater Res Bull 2002; 37(10): 1051

[37] Sahoo Y, Pizem H, Fried T, et al. Alkyl phosphonate/phosphate coating on magnetite nanoparticles: a comparison with fatty acids. Langmuir 2001; 17(25): 7907

[38] Yee C, Kataby G, Ulman A, et al. Self-assembled monolayers of alkanesulfonic and -phosphonic acids on amorphous iron oxide nanoparticles. Langmuir 1999; 15(21): 7111.

[39] Grosseau-Poussard JL, Panicau B, Pedraza F, Renault PO, Silvain JF. Iron oxidation under the influence of phosphate thin films. J Appl Phys 2003; 94(1): 784

[40] Wang HB, Shi H, Hong T, Kang C, Jepson WP. Characterization of inhibitor and corrosion product film using electrochemical impedance spectroscopy. Paper 1023. Corrosion Nace. NACE International Publication Division: Houston, Texas 2001. 